Çukurova Üniversitesi Mühendislik Mimarlık Fakültesi Dergisi, 32(2), ss. 145-152, Haziran 2017

Çukurova University Journal of the Faculty of Engineering and Architecture, 32(2), pp. 145-152, June 2017

\title{
Yumuşak Çeliğin Korozyon Davranışı
}

\author{
Başak DOĞRU MERT ${ }^{* 1}$ \\ ${ }^{I}$ Çukurova Üniversitesi, Fen Edebiyat Fakültesi, Kimya Bölümü, Adana
}

Geliş tarihi: 21.04.2017

Kabul tarihi: 31.05 .2017

\section{$\ddot{\mathbf{O} z}$}

Bu çalışmada yumuşak çeliğin (YÇ) asidik ortamındaki korozyon davranışına 3-Amino metil piridin'in (3AMP) inhibitör etkisi araştırılmışıır. Elektrokimyasal teknikler (elektrokimyasal impedans spektroskopisi ve polarizasyon ölçümleri) ve kuantum kimyasal hesaplamalar uygulanmıştır. Elde edilen sonuçlara göre; 3AMP'nin inhibisyon etkinliği artan 3AMP derişimi ile artış göstermiştir. $50 \mathrm{mM} 3 \mathrm{AMP}$ içeren $0,5 \mathrm{M} \mathrm{HCl}$ çözeltisinde inhibisyon etkinliği \%97 olarak tespit edilmiştir. Polarizasyon ölçümleri 3AMP'nin hem katodik hem de anodik reaksiyonların hızını azalttığını göstermektedir. Yüksek inhibisyon etkinliği, teorik olarak belirlenen yüksek HOMO enerjisi $(-6,937 \mathrm{eV})$, dipol momenti $(2,473 \mathrm{D})$ ve düşük LUMO enerjisi $(-1,05 \mathrm{eV})$ ile ilişkilendirilmiştir. Belirlenen Mulliken yüklere göre; $\mathrm{N}$ atomları üzerindeki negatif yük sebebiyle 3AMP'nin yumuşak çelik yüzeyine adsorpsiyonunun amin ve/veya $\mathrm{N}$ ucundan gerçekleşebileceği düşünülmektedir.

Anahtar Kelimeler: Korozyon, Yumuşak çelik, 3-Amino metil piridin

\section{The Corrosion Behavior of Mild Steel}

\begin{abstract}
In this study, the inhibition effect of 3-aminomethyl pyridine (3AMP) on mild steel corrosion behavior in acidic medium is investigated. The electrochemical techniques (electrochemical impedance spectroscopy and polarization measurements) and quantum chemical calculations were obtained. The results showed that; inhibition efficiencies increase with increasing concentration of 3AMP. The inhibition efficiency is $97 \%$ in $50 \mathrm{mM} 3 \mathrm{AMP}$ containing $0.5 \mathrm{M} \mathrm{HCl}$ solution. It is found that 3AMP retards both anodic and cathodic reactions according to polarization measurements. The high inhibition efficiency of 3AMP is attributed to the high value of EHOMO $(-6.937 \mathrm{eV})$, dipole moment $\mu(2.473 \mathrm{D})$ and low value of ELUMO (-1.049 eV). According to calculated Mulliken charges; the adsorption of 3AMP may be occurred on amine and/ $\mathrm{N}$ terminal of molecule.
\end{abstract}

Keywords: Corrosion, Mild steel, 3-aminomethyl pyridine

\footnotetext{
"Sorumlu yazar (Corresponding author): Başak DOĞRU MERT, bdogru@cu.edu.tr
} 


\section{GíRiş}

Endüstri ve mimaride en çok kullanılan metal alaşımı çeliklerdir. Gerek fiziksel ve kimyasal özellikleri, gerekse maliyeti bakımdan çokça tercih edilmektedir. Fakat bu malzemelerin kullanımını kısıtlayan ve karşılaşılan en büyük sorun ise korozyondur. Korozyon kisaca, metalik malzemelerin çevreleri ile etkileşerek doğadaki kararlı hallerine dönmesidir. Korozyonu önleme yöntemlerinden bir tanesi ve özellikle asidik çözeltiler ile temizleme işlemlerinde en çok tercih edileni de inhibitör uygulamalarıdır [1, 3]. Korozif ortama ilave edilen çeşitli inhibitör maddeler vasıtasıyla metal ve ortam arasındaki ilişki kesilir. $\mathrm{Bu}$ maddeler metal/çözelti ara yüzeyinde oluşan elektriksel alan etkisi ile metal yüzeyine fiziksel ve/veya kimyasal olarak adsorplanırlar. İnhibitör maddelerin etkinliği, kimyasal yapıları ile ilişkilidir ve OH-, -CHO, -COOH, -CN-, -SN, CO, $-\mathrm{NH}_{3}, \mathrm{SO}_{3}$ gibi gruplar, ya da çift bağ, üçlü bağ, ortaklanmamış elektronlar ihtiva eden organik maddelerin, metal ile kolayca etkileşeceği bilinmektedir [4-6]. Bu çalışmada, inhibitör madde olarak 3-Amino metil piridin'in (3AMP) yumuşak çeliğin (YÇ) korozyon davranışına etkisi araştırılmıştır. YÇ'nin 3AMP içermeyen ve içeren 0,5 $\mathrm{M} \quad \mathrm{HCl}$ çözeltilerindeki açık devre potansiyellerinin zamanla değişimi takip edilmiştir. Ayrıca farklı daldırma sürelerinde elektrokimyasal impedans spektroskopisi ve polarizasyon ölçümleri gerçekleştirilmiştir. 3AMP'nin YÇ yüzeyindeki adsorpsiyonu deneysel ve kuantum teorik yöntemlerle incelenmiştir.

\section{2. ÖNCEKİ ÇALIŞMALAR}

Literatürde piridin ve türevi bileşikler korozyona karşı inhibitör olarak sıç̧a kullanılmaktadır [1-8]. $\mathrm{Bu}$ bileşiklerin en büyük avantajı ise yapılarındaki konjuge çift bağlar ve düzlemsel yapıdaki hetero siklik halkada bulunan $\mathrm{N}$ atomudur. Bu sayede metal yüzeyine adsorpsiyon daha kolay gerçekleşebilir. Ji ve arkadaşları [1], 4-((4(bis(pyridin-2-ylmetil) amino) fenil) imino) metil)$\mathrm{N}, \mathrm{N}$-dietilanilin (BPMA) sentezleyerek $1 \mathrm{M}$ $\mathrm{HCl}$ 'de yumuşak çeliğin korozyon davranışını kütle kaybı, impedans ve polarizasyon işlemleri ile incelemişlerdir. Elde edilen bulgulara göre 303 K'de, 16 saat sonunda, inhibitör ilave edilmeyen ortamda korozyon hızı yaklaşık olarak 14,84 mm/y iken en yüksek inhibitör derişimi olan 1 M'lık BPMA çözeltisinde bu değer 1,21 mm/y olarak belirlenmiştir. $\mathrm{Bu}$ veriler ile belirlenen inhibisyon etkinliği ise \%91,9'dur. Aynı koşullarda impedans ölçümleri ile belirlenen etkinlik \%88,2’dir. Sonuç olarak BPMA'nın asidik ortamda yumuşak çeliğin korozyona karşı korunabilmesi için inhibitör olarak kullanımı önerilmiştir [1].

Ansari ve arkadaşları [2] piridin türevi olan 2amino-6-(2,4-dihidroksi fenil)-(etoksi fenil) nikotinonitril (ADP) ve 2-amino-4-(4-metoksi fenil)-6-fenil nikotinonitril (AMP) in $\% 15 \mathrm{HCl}$ çözeltisinde çeliğin korozyon davranışına etkilerini araştırmıştır. $200 \mathrm{mg} / \mathrm{L}$ inhibitör içeren çözeltilerde inhibisyon etkinlikleri yaklaşık olarak \%92 (ADP) ve \%88 (AMP) olarak tespit edilmiştir. Her iki molekülün de adsorpsiyonu Langmuir izotermine uygun olarak gerçekleşmiştir. Araştımacılar bu iki molekülün de asidik ortamda inhibitör olarak kullanımının uygun olduğunu belirtmektedir [2]. İnhibisyon etkinliği artan ADP ve AMP derişim değerleri ile artış göstermektedir.

Bouklah ve arkadaşları [8] 3,5-dimetil-1H-pirazol (P1), 3,5-dimetil-1H-piridin (P2) ve 2-(3-methil1H-pirazol-5-yl) piridin (P3) moleküllerinin inhibisyon özelliklerini $1 \mathrm{M} \mathrm{HCl}$ 'de araştırmıştır. $\mathrm{Bu}$ üç farklı kimyasal yapıdaki inhibitörler kıyaslandığında P3'ün $10^{-3} \mathrm{M}$ 'lı çözeltisinde en yüksek inhibisyon etkinliği (\%90) sergilediği tespit edilmiştir. $\mathrm{Bu}$ durum piridin ve pirazol'ün sinerjistik etkisi ile açıklanmıştır. P3'ün $\Delta \mathrm{G}_{\text {ads }}$ enerjisi oldukça yüksektir $(-42 \mathrm{kj} / \mathrm{mol})$ ve bu molekülün yüzeye kuvvetlice adsorplandığını göstermektedir [8].

$\mathrm{Bu}$ çalışmada inhibitör etkinliği araştırılan 3AMP ise yapı bakımından literatürde çalışılan [1-8] piridin türevlerinden daha küçük molekül kütlesine sahip bir kimyasal maddedir ( $M=108,14 \mathrm{~g} / \mathrm{mol})$. $\mathrm{Bu}$ durumda aynı derişim değerlerinde, diğerlerine kıyasla [1-8] daha az madde tüketimi sağlanabilir. Ayrıca 3AMP yapısında bulunan amin grubu sayesinde yumuşak çelik yüzeyine daha kuvvetli 
adsorplanabilir. Çünkü N gibi ortaklanmamış elektron çifti içeren sübstitüentler içeren yapılarda elektron yoğunluğu yüksek bölgeler sayesinde metal yüzeyine tutunma olasılığı artmaktadır [916]. 3AMP molekülü hem heterosiklik halkadaki $\mathrm{N}$ bölgesi hem de amin ucundaki $\mathrm{N}$ bölgesi sayesinde adsorpsiyonu destekleyebilir.

\section{MATERYAL VE METOT}

Deneysel çalışmalarda kullanılan yumuşak çeliğin (YÇ) kimyasal bileşimi; (\%); 0,17 C, 0,59 Si, 1,60 Mn, 0,04 P'dir. Çalışma elektrotlarının hazırlanması için silindir şeklindeki yumuşak çelik çubuktan 5'er cm boyutunda parçalar kesilmiştir. Kesilen parçaların alt yüzeylerinden bir tanesine delik açılarak bu deliğe bakır tel yerleştirilmiştir. Parçaların delik olmayan ucu açıkta kalacak şekilde polyester ile kaplanmıştır, elektrotların yüzeyi mekanik parlatıcıda uygun zımpara kağıtlarıyla (100-1200 grid) parlatıldıktan sonra 1:1 etil alkol: aseton karışımı ile temizlenmiştir. Elektrokimyasal ölçümler üç elektrot tekniğinden yararlanılarak, CHI 604 D model elektrokimyasal analiz cihazı ile gerçekleştirilmiştir. Sistemde YÇ çalışma elektrotu, platin $(\mathrm{Pt})$ karşı elektrot ve gümüş-gümüş klorür elektrot $(\mathrm{Ag} / \mathrm{AgCl}, 3 \mathrm{M} \mathrm{KCl})$ referans elektrot olarak kullanılmıştır. YÇ elektrotların zamanla değişen açık devre potansiyelleri $\left(E_{\text {ocp }}\right)$, farklı derişimlerde $(0 ; 1 ; 5 ; 10$ ve $50 \mathrm{mM}$ ) 3-Amino metil piridin (3AMP) içeren $0,5 \mathrm{M} \mathrm{HCl}$ çözeltilerine tespit edilmiştir. YÇ elektrotlara farklı daldırma sürelerinde sabit $\mathrm{E}_{\text {осp }}$ değerlerinde $10^{5}-10^{-3} \mathrm{~Hz}$ frekans aralığında, $5 \mathrm{mV}$ genlik uygulanarak ve elektrolit karıştırılmadan elektrokimyasal impedans spektroskopisi ölçümleri elde edilmiştir. Ayrıca elektrotların polarizasyon eğrileri $E_{\text {ocp }} \pm 250 \mathrm{mV}$ potansiyel aralığında $1 \mathrm{mV}$ tarama hızı ile gerçekleştirilmiştir. Kuantum teorik hesaplamalar GaussView 4.1 ve Gaussian 03W programları ile gerçekleştirilmiştir. DFT yaklaşımıyla, 6-311++G (d,p) baz seti kullanılmıştır. Belirlenen değişkenler; Mulliken atomik yükler, $\mathrm{E}_{\text {НОмо }}$ (en yüksek enerjili dolu moleküler orbital enerjisi), $\mathrm{E}_{\text {LUMO }}$ (en düşük enerjili boş moleküler orbital enerjisi), $\Delta \mathrm{E}$ ( $\mathrm{E}_{\mathrm{LUMO}}$ - $\left.\mathrm{E}_{\text {Hомо }}\right), \mu$ (dipol moment) vb.'dir.
3-Amino metil piridin'in (3AMP) yapısı Şekil 1'de verilmişstir.<smiles>NCc1cccnc1</smiles>

Şekil 1. 3-Amino metil piridin (3AMP)

\section{BULGULAR ve TARTIŞMA}

\subsection{Açık Devre Potansiyelinin Değişimi}

YÇ elektrotların 3AMP içermeyen ve içeren çözeltilerde, zamanla değişen Eocp değerleri Şekil 2'de verilmiştir. Şekil 2'de görüldüğü gibi YÇ elektrotun açık devre potansiyelinin 3AMP içeren çözeltilerde artan inhibitör derişimi ile birlikte daha soy değerlerde olduğu, bekleme süresi boyunca yaklaşık 3000-3600 s'den itibaren ise yaklaşık olarak sabit kaldığı gözlenmektedir.

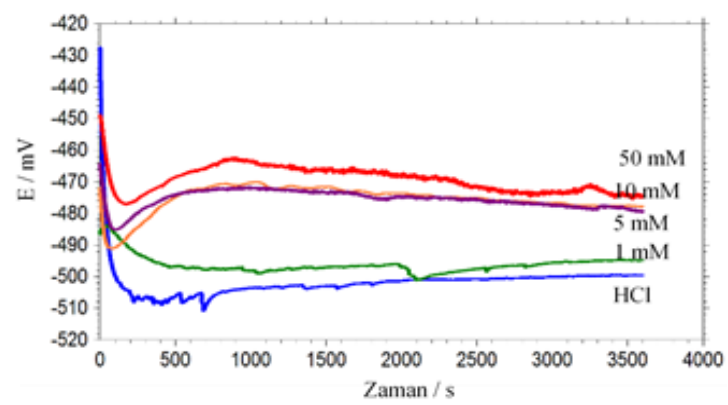

Şekil 2. YÇ elektrotların 3AMP içermeyen ve farklı derişimlerde 3AMP içeren 0,5 M $\mathrm{HCl}$ çözeltilerindeki açık devre potansiyellerinin zamanla değişimi

\subsection{Elektrokimyasal İmpedans Spektroskopisi}

YÇ'in 3AMP içermeyen ve farklı derişimlerde 3AMP içeren 0,5 M HCl'de 1 saat bekleme süresi sonunda elde edilen elektrokimyasal impedans spektrumları Şekil 3'de sunulmaktadır. Şekil 3'de görüldüğü gibi yüksek frekans bölgesinde başlayarak, orta frekans bölgesinde devam eden ve düşük frekans bölgesinde kapanan yarı eliptik eğriler tespit edilmiştir. Özellikle 3AMP içermeyen ortamda elde edilen eğri oldukça düşük faz açısına sahip ve basık eliptik bir eğridir. 
Nyquist eğrilerinden $0 ; 1 ; 5 ; 10$ ve $50 \mathrm{mM} 3$-Amino metil piridin (3AMP) içeren $0,5 \mathrm{M} \mathrm{HCl}$ çözeltilerinde belirlenen direnç değerleri sırasıyla, 39; 643; 674; 1078 ve 1308 ohm'dur (Şekil 2). Bu direnç değerleri polarizasyon direnci olup $\left(R_{p}\right)$ yük transfer direnci $\left(\mathrm{R}_{\mathrm{ct}}\right)$, yüzeydeki kaplama veya film direnci $\left(\mathrm{R}_{\mathrm{f}}\right)$ ve iyon difüzyonuna karşı gösterilen dirençleri kapsamaktadır [9]. Eğriler Şekil 3'de verilen eşdeğer devreye uygun olarak modellenmiştir ve belirlenen eşdeğer devre elemanları Çizelge 1'de sunulmaktadır. Rs çözelti direncini, CPE ise sabit faz elementini temsil etmektedir. Eğrilerin basık eliptik şekli sebebiyle modelleme CPE'ye uygun olarak yapılmıştır ve eşitlikler (1)-(3) yardımıyla çift tabaka kapasitansına $\left(\mathrm{C}_{\mathrm{dl}}\right)$ dönüştürülmüştür. $\eta \%$ değeri inhibisyon etkinliği olup eşitlik (4) yardımıyla hesaplanmıştır.

Çizelge 1. İmpedans parametreleri

\begin{tabular}{|c|c|c|c|c|}
\hline $\mathrm{C}_{\mathrm{inh}} / \mathrm{mM}$ & $\mathrm{R}_{\mathrm{s}} / \Omega$ & $\mathrm{R}_{\mathrm{p}} / \Omega$ & $\mathrm{C}_{\mathrm{dl}} / \mu \mathrm{Fcm}^{-2}$ & $\eta \%$ \\
\hline 0 & 4,9 & 39 & 151,1 & - \\
\hline 1 & 4,4 & 643 & 67,4 & 93,9 \\
\hline 5 & 4,7 & 674 & 65,8 & 94,2 \\
\hline 10 & 5,3 & 1078 & 63,2 & 96,4 \\
\hline 50 & 4,9 & 1308 & 44,6 & 97,0 \\
\hline
\end{tabular}

$Z_{C P E}=\frac{1}{Y_{0}(J \omega)^{n}}$

$\omega=\left(\frac{1}{R_{c t} Y_{0}}\right)^{1 / n}$

$C_{d l}=\frac{Y_{0} \omega^{n-1}}{\sin \left(\frac{n \pi}{2}\right)}$

$\eta \%=\left(\frac{R_{p}^{\prime}-R_{p}}{R_{p}^{\prime}}\right) \times 100$

Eşitliklerde (1)-(4), Yo ve n, frekanstan bağımsız parametreler olup, $-1 \leq \mathrm{n} \leq 1$ dir. $\omega$ impedansın imajinal bölümünün açısal frekansıdır. $R_{p}$ and $R_{p}$ sırasıyla inhibitörsüz ve inhibitörlü ortamdaki direnç değerleridir. 3AMP derişimi ile direnç değerleri artmış ve $\mathrm{C}_{\mathrm{dl}}$ değerleri azalmıştır. En yüksek inhibisyon etkinliği $50 \mathrm{mM} 3 \mathrm{AMP}$ içeren ortamda $\% 97$ olarak belirlenmiştir.

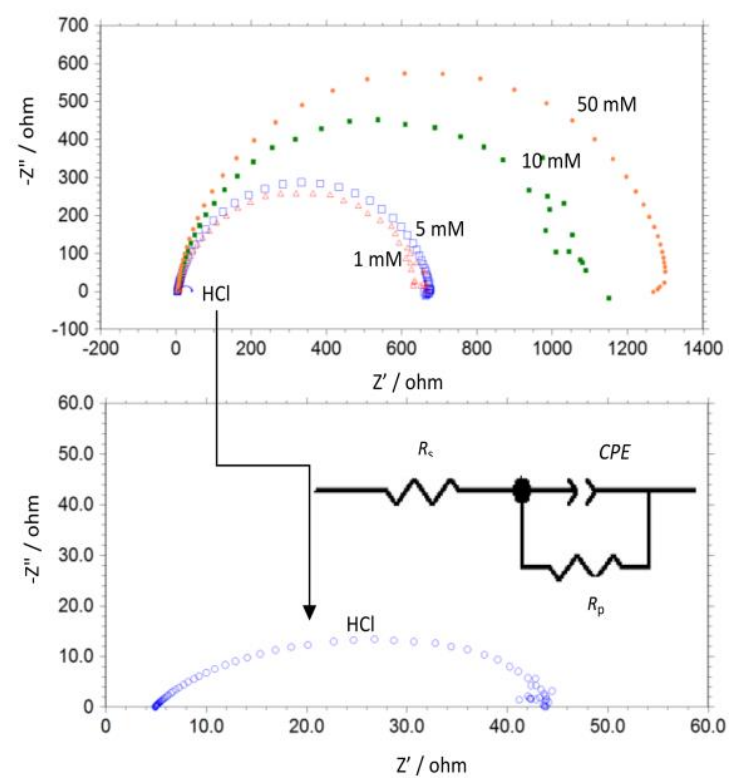

Şekil 3. YÇ elektrotların 3AMP içermeyen ve farklı derişimlerde 3AMP içeren 0,5 M $\mathrm{HCl}$ çözeltisinde 1 saat bekleme süresi sonunda elde edilen Nyquist eğrileri ve eşdeğer devre modeli

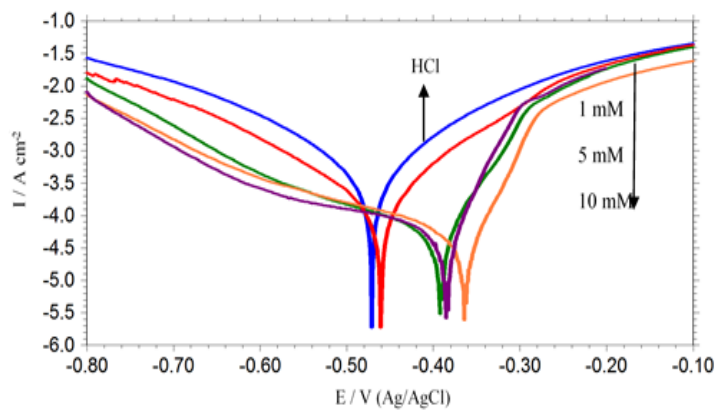

Şekil 4. YÇ elektrotların3AMP içermeyen ve farklı derişimlerde 3AMP içeren 0,5 M $\mathrm{HCl}$ çözeltisinde 1 saat bekleme süresi sonunda elde edilen polarizasyon eğrileri

\subsection{Polarizasyon Ĕ̆rileri}

YÇ'in 3AMP içermeyen ve içeren 0,5 $\mathrm{M} \mathrm{HCl}$ 'de 1 saat bekleme süresi sonunda elde edilen polarizasyon eğrileri Şekil 4'de görülmektedir. YÇ’nin polarizasyonu sırasında 3AMP içeren ortamlarda sistemden geçen akım yoğunluğu değerlerinin içermeyen ortama kıyasla çok daha 
düşük olduğu görülmektedir. $5 \mathrm{mM}$ ve üzerindeki derişimler için güvenilir Tafel bölgesi tespit edilemediğinden dolayı korozyon akımı ve potansiyeli kesin olarak hesaplanamamaktadır. Fakat artan 3AMP derişimine bağlı olarak korozyon potansiyeli değerlerinin daha soy değerlere kaydığı açıkça görülmektedir.

\subsection{Zamanla Değişen İnhibitör Etkinliği}

Elektrokimyasal ölçümler sırasında sistemin denge potansiyeline ulaşması için gereken süre 1 saat olarak tespit edildiği için (Şekil 2), gerek elektrokimyasal impedans spektroskopisi ölçümleri (Şekil 3), gerekse polarizasyon eğrileri (Şekil 4) bu koşullarda elde edilmiştir. Fakat endüstriyel uygulamalar dikkate alındığında inhibitör seçimi yapılırken uzun uygulama sürelerindeki performans oldukça önem arz etmektedir. $\mathrm{Bu}$ sebeple 1-168 saat daldırma sürelerinde 3AMP içermeyen ve içeren ortamlardaki etkinlik değerleri belirlenmiştir. Elde edilen Nyquist eğrileri Şekil 5'de görülmektedir.
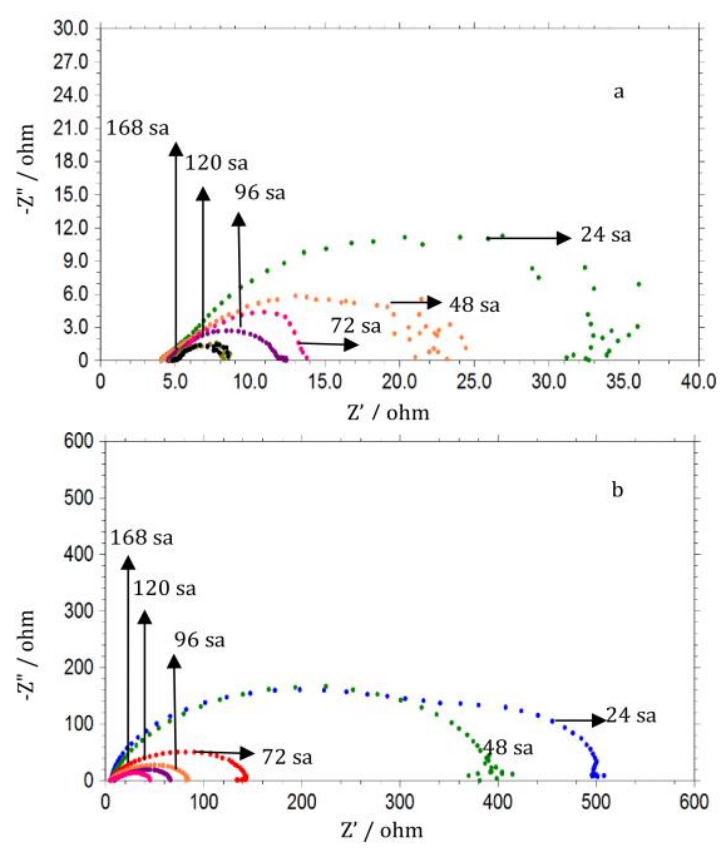

Şekil 5. YÇ elektrotların 3AMP içermeyen (a) ve $50 \mathrm{mM}$ 3AMP içeren (b) $0,5 \mathrm{M} \mathrm{HCl}$ çözeltilerinde farklı daldırma sürelerinde elde edilen Nyquist eğrileri
Şekil 5'de görüldüğü gibi artan bekleme süresi ile 3AMP içermeyen ve içeren ortamlarda direnç değerleri azalmıştır. $\mathrm{Bu}$ durum korozif ortamla uzun süre temas eden metalin çözünmesinden ve metal çözelti ara yüzeyine iç Helmholtz tabakaya kadar spesifik adsorplanabilen $\mathrm{Cl}^{-}$iyonlarının aşındırıcı etkisinden kaynaklanabilir [9]. 3AMP içeren ortamda YÇ'nin direnç değerlerinin (Rp'), içermeyen ortama (Rp) kıyasla çok daha yüksek olduğu görülmektedir. Eşitlik 4 yardımıyla belirlenen inhibisyon etkinliğinin zamanla değişimi Çizelge 2'de verilmiştir.

Çizelge 2.1-168 saat daldırma süreleri sonunda elektrokimyasal impedans spektroskopisi ölçümlerinden belirlenen inhibisyon etkinlikleri

\begin{tabular}{|c|c|c|c|}
\hline $\mathrm{t} / \mathrm{sa}$ & $\mathrm{R}_{\mathrm{p}} / \Omega$ & $\mathrm{R}_{\mathrm{p}} / \Omega$ & $\eta \%$ \\
\hline 24 & 33,2 & 503,5 & 93,4 \\
\hline 48 & 24,6 & 401 & 93,9 \\
\hline 72 & 14,2 & 144 & 90,1 \\
\hline 96 & 12,4 & 80,8 & 84,7 \\
\hline 120 & 8,6 & 63,5 & 86,5 \\
\hline 168 & 8,2 & 42,8 & 80,8 \\
\hline
\end{tabular}

Çizelge 2'de görüldüğü gibi 3AMP YÇ'nin 0,5 M $\mathrm{HCl}$ çözeltisinde korozyon davranışına uzun daldırma süreleri boyunca (168 sa) inhibisyon etkisi göstermektedir. 3AMP'nin YÇ yüzeyine adsorpsiyonunun incelenmesi amaciyla adsorpsiyon izotermlerinden yararlanılmış ve en uygun olanın Langmuir adsorpsiyon izotermi olduğu belirlenmiştir (Şekil 6).

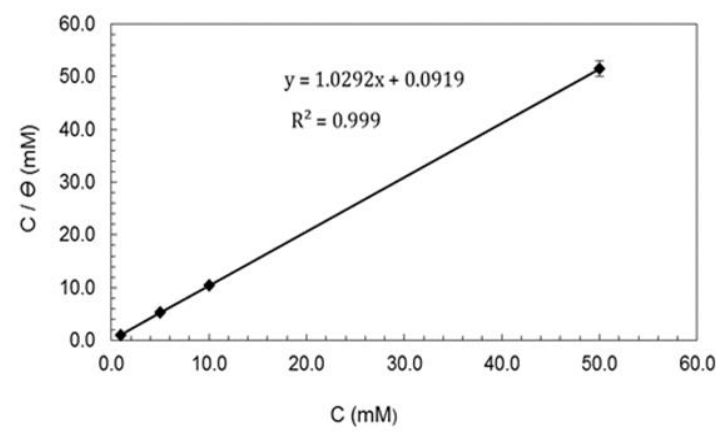

Şekil 6. YÇ'nin farklı derişimlerde 3AMP içeren $0,5 \mathrm{M} \mathrm{HCl}$ çözeltilerinde elde edilen Langmuir adsorpsiyon izotermi 


$$
\frac{\mathrm{C}_{\mathrm{inh}}}{\theta}=\frac{1}{\mathrm{~K}_{\mathrm{ads}}}+\mathrm{C}_{\mathrm{inh}}
$$

Eşitlik 5'de $\mathrm{C}_{\text {inh }}$ inhibitör derişimini, $\theta$ yüzey kaplanma kesrini, $K_{a d s}$ ise adsorpsiyon denge sabitini temsil etmektedir [10-13]. Şekil 6'da, Eşitlik 5 yardımıyla belirlenen $\mathrm{K}_{\mathrm{ads}}$ değeri $10,88 \times 10^{3} \mathrm{M}^{-1}$ dir. $\mathrm{Bu}$ değerin büyüklüğü 3AMP'nin YÇ yüzeyine oldukça güçlü adsorplandığını göstermektedir. Eşitlik 6 yardımıyla belirlenen $\Delta G_{\text {ads }}^{o}$ değeri ise yaklaşık 33 $\mathrm{kJ} \mathrm{mol}^{-1}$ olarak hesaplanmıştır ve bu değer adsorpsiyonun fiziksel olarak gerçekleştiğini göstermektedir [14-16].

$$
\Delta G_{a d s}^{0}=-R T \ln \left(55.5 K_{a d s}\right)
$$

\subsection{Kuantum Teorik Hesaplamalar}

3AMP'nin YÇ yüzeyinde adsorpsiyonunun aydınlatılması amaciyla kuantum teorik hesaplamalar gerçekleştirilmiştir. Bu amaçla DFT yaklaşımıyla, 6-311++G (d,p) baz seti kullanılmıştır. 3AMP için en düşük enerjili boş orbital (LUMO) enerjisi $-1,05 \mathrm{eV}$; en yüksek enerjili dolu orbital (HOMO) enerjisi -6,937 eV olarak hesaplanmıştır. Bu orbitaller Şekil 7'de görülmektedir. Ayrıca 3AMP için belirlenen yüksek dipol moment değeri $(2,473$ D), bu molekülün YÇ yüzeyine adsorpsiyonunun kolay bir şekilde gerçekleşebileceğini göstermektedir [16].

3AMP moleküllerinin, asidik ortamda pozitif yükle yüklenmiş olan YÇ yüzeyine, negatif uçlardan yaklaşacağı düşünülmektedir. Elde edilen Mulliken yük değerleri incelendiğinde; 3AMP'deki amin grubu üzerinde yer alan $\mathrm{N}$ atomunun $-0,353$ a.u. yükü sebebiyle, adsorpsiyonun molekülün bu grubu vasitasiyla gerçekleşmiş olabileceği düşünülmektedir.

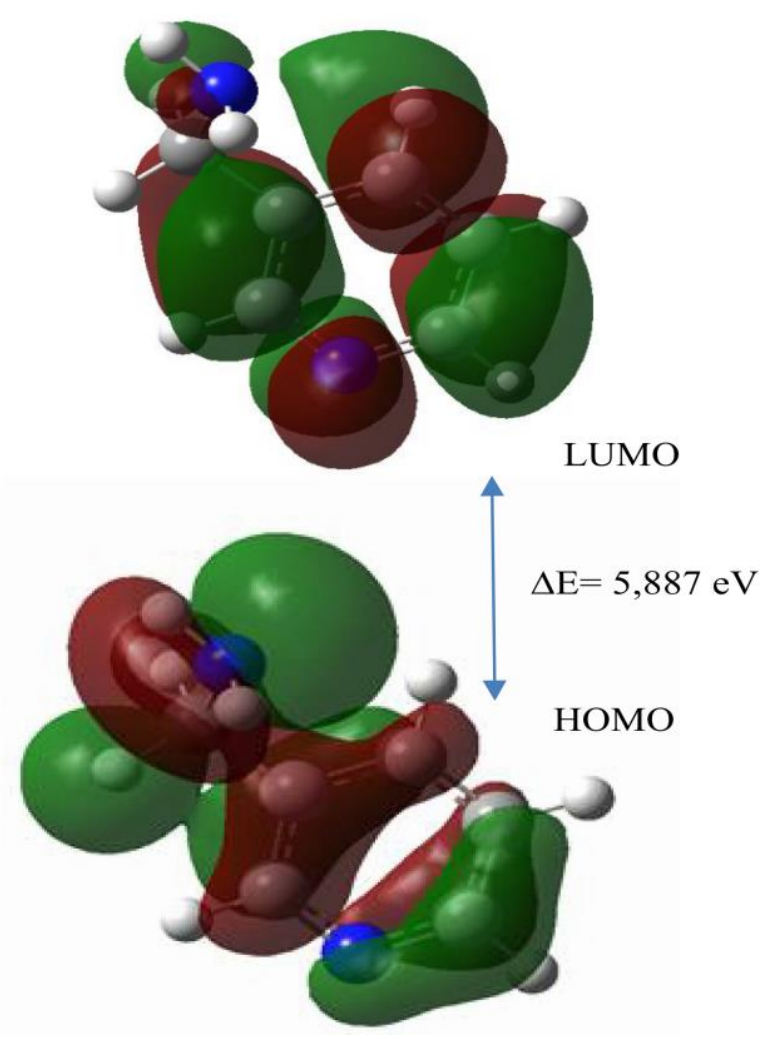

Şekil 7. 3AMP'nin LUMO ve HOMO şekilleri 
Sonuç olarak; 3AMP'nin 0,5 M HCl içeren çözeltilerde yumuşak çeliğin korozyona karşı korunması amacıyla kullanılabileceği ve etkinliği yüksek bir inhibitör olduğu tespit edilmiştir. 3AMP'nin literatürde yer alan diğer piridin türevleri ile kıyaslanması açısından inhibisyon etkinlikleri Çizelge 3'de verilmiştir. Buna göre 3AMP, literatürdeki birçok piridin türevinden daha etkili bir inhibitördür ve endüstriyel uygulamalarda özellikle asidik temizleme banyolarında kullanımı tavsiye edilmektedir.

Çizelge 3. Piridin türevi bileşiklerin inhibisyon etkinlikleri

\begin{tabular}{|l|c|c|}
\hline Molekül & Etkinlik* $\%$ & Kaynaklar \\
\hline BPMA & 91,9 & {$[1]$} \\
\hline ADP & 92,0 & {$[2]$} \\
\hline AMP & 88,0 & {$[2]$} \\
\hline TPP & 94,3 & {$[3]$} \\
\hline P2T & 97,5 & {$[4]$} \\
\hline 2PD & 96,7 & {$[4]$} \\
\hline PC-1 & 97,4 & {$[5]$} \\
\hline PC-2 & 95,7 & {$[5]$} \\
\hline PC-3 & 88,0 & {$[5]$} \\
\hline P1 & 94,0 & {$[6]$} \\
\hline P2 & 87,0 & {$[6]$} \\
\hline TODPCN & 60,5 & {$[7]$} \\
\hline TODPCN+ KI & 97,5 & {$[7]$} \\
\hline P1 & 32,0 & {$[8]$} \\
\hline P2 & 13,0 & {$[8]$} \\
\hline P3 & 91,0 & {$[8]$} \\
\hline 3AMP & 97 & Bu çalısmada \\
\hline
\end{tabular}

*Çizelge 3'deki etkinlik değerleri her bir araştırmada belirtilen inhibitör maddelerin en yüksek derişimleri için elde edilmiştir.

\section{KAYNAKLAR}

1. Ji, Y., Xu B., Gong, W., Zhang, Z., Jin, X., Ning W., Meng Y., Yang W., Chen Y., 2016. Journal of the Taiwan Institute of Chemical Engineers: Corrosion Inhibition of a New Schiff Base Derivative With Two Pyridine Rings on Q235 Mild Steel in 1.0 M HCl, 66, p. 301-312.

2. Ansari, K., Quraishi, M.A., Singh, A., 2015. Measurement: Pyridine Derivatives As
Corrosion Inhibitors for N80 Steel in $15 \% \mathrm{HCl}$ : Electrochemical, Surface and Quantum Chemical Studies, 76, p. 136-147.

3. Singh, P., Quraishia, M.A., Gupta, S.I., Dandi, A., 2016. Journal of Taibah University for Science: Investigation of The Corrosion Inhibition Effect of 3-Methyl-6-Oxo-4(Thiophen-2-Yl)-4,5,6,7-Tetrahydro-2H-

Pyrazolo[3,4-B]Pyridine-5-Carbonitrile (TPP) On Mild Steel in Hydrochloric Acid, 10, p. 139-147.

4. Kosari, A., Moayed, M.H., Davoodi, A., Parvizi, R., Momeni, M, Eshghi, H, Moradi, H., 2014. Corrosion Science: Electrochemical and Quantum Chemical Assessment of Two Organic Compounds From Pyridine Derivatives as Corrosion İnhibitors For Mild Steel in $\mathrm{HCl}$ Solution Under Stagnant Condition And Hydrodynamic Flow. 78, p. 138-150.

5. Ansari, K., Quraishi, M.A., Singh, A., 2015. Journal of Industrial and Engineering Chemistry: Corrosion Inhibition of Mild Steel in Hydrochloric Acid By Some Pyridine Derivatives: An Experimental And Quantum Chemical Study, 25, p. 89-98.

6. Tebbji, K., Ouddac, H., Hammouti, B., Benkaddour M., Kodadi M., Ramdani A., 2005. Colloids and Surfaces A: Inhibition Effect of Two Organic Compounds PyridinePyrazole Type In Acidic Corrosion of Steel, 259, p. 143-149.

7. Mourya, P., Sing, P., Rastog, R., Singh, M., 2016. Applied Surface Science: Inhibition of Mild Steel Corrosion By 1,4,6-Trimethyl-2Oxo-1,2-Dihydropyridine-3-Carbonitrile And Synergistic Effect of Halide Ion in $0.5 \mathrm{M}$ $\mathrm{H}_{2} \mathrm{SO}_{4}, 380$, p. 141-150.

8. Bouklah, M., Attayibat, A., Hammouti, B., Ramdani, A., Radi S., Benkaddour M., 2005. Applied Surface Science: Pyridine-Pyrazole Compound as Inhibitor for Steel in $1 \mathrm{M} \mathrm{HCl}$, 240, p. 341-348.

9. Bockris, J.O., Reddy, A.K.N., Gamboa A.M., 2000. Modern electrochemistry Fundamentals of electrodics. $2^{\text {nd }}$ ed., New York, USA.

10. Scendo, M., Trela, J., 2013. Journal of Electrochemical Science: Adenine as an 
Effective Corrosion Inhibitor for Stainless Steel in Chloride Solution, p. 9201-9221.

11. Deng, S., Li, X., Xie, X., 2014. Corrosion Science: Hydroxymethyl Urea And 1,3-Bis (Hydroxymethyl) Urea as Corrosion Inhibitors for Steel in $\mathrm{HCl}$ Solution, 80 p. 276-289.

12. Khamis, A., Saleh, M.M., Awad, M.I., ElAnadouti, B.E., 2013. Corrosion Science Enhancing The Inhibition Action of Cationic Surfactant with Sodium Halides For Mild Steel in $0.5 \mathrm{M} \mathrm{H} 2 \mathrm{SO} 4,74$, p. 83-91.

13. Li, X., Deng, S., Fu, H., Xie, X., 2014. Corrosion Science Synergistic Inhibition Effects of Bamboo Leaf Extract/Major Components and Iodide Ion on The Corrosion of Steel in $\mathrm{H}_{3} \mathrm{PO}_{4}$ solution, 78, p. 29-42.

14. Yadav, M., Sinha, R.R, Kumar, S., Bahadur, I., Ebenso E.E., 2015. Journal of Molecular Liquids: Synthesis And Application of New Acetohydrazide Derivatives as a Corrosion Inhibition of Mild Steel in Acidic Medium: Insight From Electrochemical And Theoretical Studies, 208, p. 322-332.

15.Zhanga, D., Tanga, Y., Qia, S., Donga, D., Cang, H., Lu, G., 2016. Corrosion Science: The Inhibition Performance of Long-Chain AlkylSubstituted Benzimidazole Derivatives For Corrosion of Mild Steel in $\mathrm{HCl}, 102$, p. 517-522.

16. Yüce, A., Telli, E., Doğru Mert, B., Kardaş, G., Yazic1, B., 2016. Journal of Molecular Liquids: Experimental and Quantum Chemical Studies on Corrosion Inhibition Effect of 5,5 Diphenyl 2-Thiohydantoin on Mild Steel in $\mathrm{HCl}$ Solution, 218, p. 384-392. 